\title{
EDUCAÇÃO DAS RELAÇÕES ÉTNICO-RACIAIS NA RESIDÊNCIA PEDAGÓGICA DE SOCIOLOGIA
}

Cleyde Rodrigues AMORIM Universidade Federal do Espírito Santo (UFES)

Vitória, Espírito Santo - Brasil cleyde.amorim@ufes.br ORCID:https://orcid.org/000-0001-9669-2459

Yamilia de Paula SIQUEIRA Universidade Federal do Espírito Santo (UFES)

Vitória, Espírito Santo - Brasil yamilia.siqueira@gmail.com ORCID:https://orcid.org/0000-0002-7853-0090

\begin{abstract}
Resumo: Este texto objetiva discutir a formação de professores de Sociologia, no Programa Residência Pedagógica - Sociologia, e em especial a formação voltada para a educação das relações étnico-raciais. O Programa foi subsidiado pela agência governamental CAPES por 18 meses (2018/2020), e desenvolvido em uma escola pública de ensino médio em Vila Velha, região metropolitana de Vitória/ES. Para este trabalho nos utilizamos da pesquisa participante, observações e entrevistas. Os resultados do Programa Residência Pedagógica foram significativos para a formação dos licenciandos e para a formação continuada dos professores envolvidos, além de dinamizar as atividades didático-pedagógicas na escola. O estudo também apontou para a necessidade e importância da formação como fator preponderante para a discussão da história e cultura africana e afro-brasileira, prevista pela Lei 10.639/2003 no ensino brasileiro.
\end{abstract}

Palavras-chave: Sociologia no ensino médio. Programa residência pedagógica. educação étnico-Racial. Formação de Professores. Sociologia antirracista.

\section{EDUCATION OF ETHNIC-RACIAL RELATIONSHIPS IN THE PEDAGOGICAL RESIDENCE OF SOCIOLOGY}

\begin{abstract}
This text aimstodiscuss the training of Sociology teachers, in thePedagogicalResidencyProgram - Sociology, and in particular the training aimedattheeducationofethnic-racial relations. The Programwassubsidizedbythegovernmentagency CAPES for 18 months (2018/2020), anddeveloped in a public high school in Vila Velha, metropolitanregionof Vitória/ES/Brazil. For thisworkwe use participantresearch, observationsand interviews. The resultsofthePedagogicalResidencyProgramweresignificant for the training ofundergraduatestudentsand for thecontinuingeducationoftheteachersinvolved, in additiontoboostingdidacticandpedagogicalactivitiesatschool. The studyalsopointedtotheneedandimportanceof training as a major factor in thediscussionofAfricanand Afro-Brazilianhistoryandculture, provided for by Law 10.639 / 2003 in Brazilianeducation.
\end{abstract}

keywords: Sociology in high school. Pedagogicalresidenceprogram. Ethnic-racial education. Teacher training.Anti-racistsociology. 


\section{EDUCACIÓN DE RELACIONES ÉTNICO-RACIALES EN LA RESIDENCIA PEDAGÓGICA DE SOCIOLOGÍA}

Resumen: Este texto tiene como objetivo discutir laformación de docentes de Sociología, en Programa de Residencia Pedagógica - Sociología, y en particular laformación dirigida a laeducación de las relaciones étnico-raciales. El Programa fue subvencionado por la agencia gubernamental CAPES durante 18 meses (2018/2020) y se desarrollóen una escuela secundaria pública en Vila Velha, región metropolitana de Vitória/ ES/Brasil. Para este trabajo utilizamos investigaciones, observaciones y entrevistas de los participantes. Los resultados del Programa de Residencia Pedagógica fueron significativos para laformación de losestudiantes de pregrado y para laformación continua de los docentes involucrados, además de potenciar lasactividadesdidáctico-pedagógicas enlaescuela. El estudiotambiénseñalólanecesidad e importancia de laformación como unfactor importante para ladiscusión de la historia y la cultura africana y afrobrasileña, prevista por laLey 10.639 / 2003 enlaeducaciónbrasileña.

Palabras clave: Sociologíaenlaescuela secundaria. Programa de residencia Pedagógica. Educación étnico-racial. Formación de professores.Sociología antirracista. 


\section{Introdução}

O ensino de Sociologia na educação básica no Brasil é uma história que pode ser contada por muitas tentativas e interrupções, que passam de um século, e que já foram relatadas por diversos autores, comoMeucci (2000) e Silva (2007). Um outro fator histórico no âmbito do ensino superior, também deixou marcas deletérias nas licenciaturas - o Decreto-Lei n.1190 de 1939. Essa norma legal organizou os cursos de licenciatura, com a função de formar bacharéis e licenciados, instituindo o chamado "padrão federal", que passou a nortear a definição dos currículos básicos das demais instituições do país a partir de então. O decreto definiu o chamado modelo $3+1$, no qual se destinava três anos para formação de bacharéis e mais um ano de didática para licenciandos. Essa concepção dicotômica que se faz presente até hoje e distancia a prática de ensino dos cursos de formação docente, preterindo a formação pedagógica (BARREIRO; GEBRAN, 2006, p. 37-41).

Muito embora outras reformas já tenham ocorrido e os currículos tenham sido reformulados, com um substantivo aumento das disciplinas e da carga horária destinada às licenciaturas, a formação de professores ainda se constitui um grande desafio para os cursos de licenciatura. A inserção na escola é um momento importante da formação, e que pode promover no discente uma autorreflexão sobre o seu campo profissional. $\mathrm{Na}$ escola, apontam-se possibilidades para a ruptura da dualidade teoria/prática, que para Pimenta e Lima (2006, p.7) sempre devem ser tratadas como uma unidade, uma vez que "essa contraposição entre teoria e prática não é meramente semântica, pois se traduz em espaços desiguais de poder na estrutura curricular, atribuindo-se menor importância à carga horária denominada de 'prática'." Essa visão distorcida da licenciatura como formação acessória ao bacharelado, pela falsa suposição de que não demanda pesquisa, em muitos casos promove entre os discentes uma concepção utilitária da formação de professores e desmotiva os estudantes a cursarem essa habilitação.Um dos fatores responsáveis por essa visão pode ter sido certa hierarquização entre o bacharelado e a licenciatura, promovendo um desequilíbrio e o desfavorecimento da segunda (MORAES, 2003).

Outra consequência desse complexo processo de institucionalização das Ciências Sociais e da disciplina Sociologia no ensino básico, e da sua consequente instabilidade nos currículos, é a dificuldade de compreensão, por parte do corpo escolar, de sua necessidade na composição deste ciclo de estudos (SILVA, 2007). Um dos argumentos utilizados no debate sobre essa inserção recaía justamente sobre a dissensãosobre a formação de professores nos cursos de graduação.

Como parte da Política Nacional de Formação de Professores do Ministério da Educação (MEC), a Coordenação de Aperfeiçoamento de Pessoal de Nível Superior - CAPES, já contava com algumas iniciativas, como o Programa Institucional de Bolsa de Iniciação à Docência (PIBID)1. Dentro desta política, foi criado em 2018 o Programa de Residência Pedagógica- PRP, que iniciou as atividades em agosto daquele ano. Esse Programa tem o intuito de incrementar a formação de professores, aproximando o licenciando de seu campo de trabalho e estreitando os laços entre Instituições de Ensino Superior - IES e escolas públicas. Visa também "o aperfeiçoamento da formação prática nos cursos de licenciatura, promovendo a imersão do licenciando na escola de educação básica, a partir da segunda metade de seu curso"2 (CAPES, 2020). A primeira edição doPRP foi subsidiada por 18 meses (agosto/2018 - janeiro/2020), contemplando licenciandos - residentes, professores do ensino básico - preceptores, e professores das IES na coordenação dos projetos institucionais e dos subprojetos por áreas de ensino - docentes orientadores.

1 O PIBID foi criado em 2007 para promover a formação inicial de docentes, e posteriormente regulamentado pelo Decreto n. ${ }^{\circ} 7.219 / 2010$ e pela Portaria 096/2013.

$2 \mathrm{https} / /$ capes.gov.br/educacao-basica/programa-residencia-pedagogica. 
Com o objetivo de promover a formação inicial de professores e intensificar o diálogo promovido pelas Ciências Sociais no ensino básico, participamos dessa primeira edição do PRP na Universidade Federal do Espírito Santo (UFES) com um subprojeto na disciplina Sociologia. Este subprojeto3 buscou o desenvolvimento de práticas docentes e experiências metodológicas inovadoras e interdisciplinares, valorizando a criatividade dos residentes e dos estudantes. Assim as possibilidades didático-pedagógicas para o ensino da disciplina Sociologia poderiam contar com a experimentação e trazer como aliadas as novas tecnologias.

Embora a educação para as relações étnico-raciais estivesse apenas contemplada dentro dos temas que a Sociologia trabalha na escola, o tema mostrou-se um dos mais necessários e por isso encontrou respaldo no maior número de propostas de trabalho dos residentes para as atividades. Por isso trouxemos para esse texto uma breve análise da produção e dos itinerários formativos dos residentes a partir deste processo de formação com interface na discussão das relações étnico-raciais brasileiras.

Dentro do PRP, o subprojeto Sociologia envolveu as atividades de ensino, pesquisa e extensão, o que nos requereu como perspectiva metodológica a observação participante. Como recursos metodológicos para a as ações desenvolvidas e seus desdobramentos, utilizamos as observações realizadas na escola-campo, anotações emdiário de campo, entrevistas e conversas informais com os residentes e com os demais atores da escola envolvidos no processo.

Buscamos com a observação participante, estabelecer o diálogo com os residentes e profissionais da rede de ensino e conhecer os seus universos de formação. Dentro de uma perspectiva etnográfica, a observação participante exige um olhar sensível à realidade do campo da pesquisa e, segundo James Clifford (2008):

Obriga os seus participantes a experimentar, tanto em termos físicos quanto intelectuais as vicissitudes da tradução. Ela requer um árduo aprendizado linguístico, algum grau de envolvimento direto e conversação, e frequentemente um "desarranjo" das expectativas pessoais e culturais [...] (CLIFFORD, 2008, p. 20).

Em relação à abordagem etnográfica, é importante ressaltar a descrição realizada por Malinowski em que ele deixa claro que a primeira meta do trabalho de campo etnográfico "é fornecer um esquema claro e firme da constituição social, bem como destacar as leis e normas de todos os fenômenos culturais, libertando-os dos aspectos irrelevantes". (MALINOWSKI, 1973, p. 24). Dessa forma, é que a relação com a escola-campo foi se estabelecendo, em contato direto com os licenciandos e demais atores da escola.

Com a etnografia na escola, foi possível reunir uma série de percepções, relatos e situações significativas, por meio do diário de campo,onde"a prática etnográfica [se deu] no contexto de estabelecer relações, selecionar informantes, transcrever textos, levantar genealogia, mapear campos, manter um diário, e assim por diante" (GEERTZ, 2008, p.11), visando contextualizar os universos de sentido ali presentes.

A partir desse caminho metodológico, objetivamos neste trabalho discutir a formação de professores de Sociologia, na primeira edição do Programa Residência Pedagógica - Sociologia, e em especial os desdobramentos da formação quanto a educação das relações étnico-raciais.

3 Devido ao não preenchimento de todas as 30 vagas, compusemos o subprojeto multidisciplinar Sociologia-História. Após a fase inicial essas áreas desenvolveram as atividades de forma independente em suas escola-campo. 


\section{Constituindo residentes pedagógicos e preceptor: o início da formação}

Após a seleção da escola, do professor preceptor e dos onze residentes4(10 bolsistas e um voluntário), as atividades iniciaram com um ciclo de formação5e em seguida, de ambientação na escola. Para a fase inicial, que foi realizada juntamente com as áreas de História e Geografia, as discussões se focaram: nos objetivos da Residência Pedagógica e seu planejamento geral; no papel do professor, envolvendo as questões éticas e as atividades no âmbito da escola; no referencial curricular do estado, e na Base Nacional Comum Curricular (BNCC). Na fase de ambientação foram realizados os planejamentos de atividades, tanto na escola como nas reuniões de equipe, e se iniciaram as regências dos residentes, seguindo as diretrizes da Secretaria Estadual de Educação e o planejamento do professor preceptor para a disciplina e período.

Um dos objetivos do PRP é a integração entre a universidade e as escolas. Nesse quesito, muito embora o órgão gestor estadual estivesse ciente da existência e execução do Programa, e dele tenha sido partícipe, observamos que não houve comunicação entre a Secretaria Estadual de Educação e as escolas públicas, que ficaram sabendo do PRP e dos editais por meio de contatos pessoais feitos por docentes e estudantes da universidade. Além dessa falta de comunicação, esse órgão não deu nenhum suporte ao desenvolvimento das atividades, que ficaram inteiramente a cargo da Ufes e das escolas. Ainda assim, as escolas foram receptivas e autorizaram a execução do projeto, além de liberarem os professores para as atividades formativas na universidade. Há de se destacar ainda a dificuldade inicial da escola em entender o funcionamento do projeto, uma vez que não tinha informações prévias a respeito. Superados os obstáculos iniciais, as atividades tiveram boa aceitação.

O lócus das atividades foi uma escola públicade ensino médio, localizada em Vila Velha, município que compõe a região metropolitana da capital Vitória/ES. Esta escola atende cerca de mil estudantes (1074 em 2019) de diversos bairros do entorno, provenientes de classe média baixa, e em menor número de outros bairros com maior vulnerabilidade social. Ela tem boa estrutura física e conta com a maioria de professores concursados, o que não é comum em muitas outras escolas públicas da região. Na escola, as ações didático-pedagógicas foram planejadas e executadas em conjunto com o professor preceptor e tiveram a adesão de alguns professores convidados ao trabalho interdisciplinar, especialmente os das áreas de português/literatura, artes e educação física. Outros professores participaram de momentos de formação continuada na escola, nas discussões sobre: a reforma do ensino médio; a BNCC, e o uso de recursos educacionais para a educação das relações étnico-raciais. Na disciplina Sociologia, as atividades abrangeram o conteúdo previsto para as três séries do ensino médio, e os dois turnos de funcionamento da escola (matutino e vespertino).

\section{A questão étnico-racial na escola: desafios e desdobramentos interdisciplinares}

Dentro da carga horária a ser cumprida na regência de aulas (100 h), para além dos temas presentes no planejamento do Professor Preceptor, a discussão étnico-racial foi realizada por meio dos temas da Sociologia que estavam previstos no currículo estadual do Espírito Santo, disponível no site da Secretaria Estadual de Educação (SEDU) e também por meio de atividades complementares como pesquisa e extensão na escola.

\footnotetext{
4 A seleção foi por edital público e, para os residentes os critérios envolviam o coeficiente de rendimento, o pertencimento étnico-racial declarado (pretos, pardos e indígenas) e a renda per capita familiar (declarada na matrícula). Disponível em http://prograd.ufes.br/sites/prograd.ufes.br/files/field/anexo/ edital_08-2018__bolsas_para_estudantes.pdf

5 A formação teve como tema inicial os cuidados éticos para com todos os envolvidos direta ou indiretamente no projeto (professores, estudantes, gestores, servidores), respeitando o ambiente e a comunidade escolar e a busca de uma perspectiva colaborativa. Todas as atividades que demandaram uso de informações dos estudantes ou do corpo escolar, bem como imagens/vozpassaram pelos protocolos éticos exigidos pela gestão pelas instituições envolvidas (escola, secretaria de educação e UFES) e obedeceram os procedimentos de ética em pesquisa e ações de ensino e extensão.
} 
Para tanto foram utilizadas além do espaço das salas de aula, áreas externas e horários alternativos, inclusive para produção de materiais para a Mostra Cultural da escola. Quanto ao tratamento da questão étnico-racial na disciplina, podemos classificar três tipos de abordagens nas diferentes atividades desenvolvidas:

1 - a questão passou por discussões que foram o tema da aula ou atividade didático-pedagógica, ocupando parte significativa das atividades com estudantes (até 50\%); Foram pautados temas como: desigualdade racial no mercado de trabalho brasileiro; o racismo em frases e falas contemporâneas, etc;

2 - a questão foi abordada dentro da discussão de temas transversais, tais como: representação política de minorias no legislativo; cidadania, democracia e direitos humanos; movimentos sociais e partidos políticos; as condições de trabalho; sistemas de governo; trabalho infantil, reforma trabalhista no Brasil e profissões do futuro; identidades e diversidades culturais; a cultura regional e no Brasil; violência no país e o Atlas da Violência 2019; desigualdades sociais; outras discussões com interseccionalidade entre raça, gênero e sexualidade.

3 - a questão foi o eixo principal das atividades desenvolvidas por dois residentes, como tema de seus projetos de intervenção, envolvendo diversas atividades didático-pedagógicas.

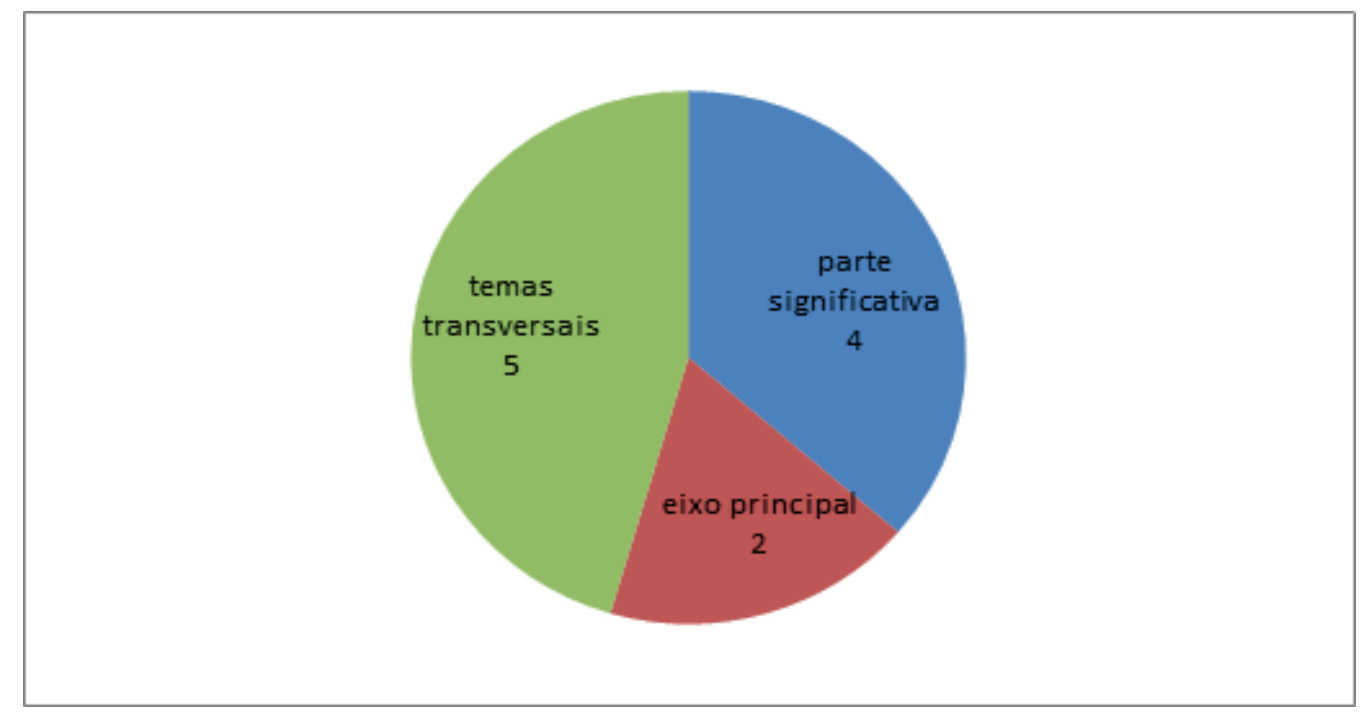

Fonte: Dados do Residência Pedagógica Sociologia.

Como vimos, de um modo ou de outro, todos os residentes passaram pela temática, entretanto dois deles tiveram a questão étnico-racial como referência para o desenvolvimento de todas as atividades na escola, caracterizando o eixo central de suas atividades didático-pedagógicas, com as abordagens que seguem.

\section{Encontros com a cultura e identidade afro-brasileira}

As atividades desenvolvidas nesse eixo foram interdisciplinares entre Sociologia e Educação Física, consistindo em ensino e extensão, com foco na história e cultura africana e afro-brasileira e na capoeira. Foram realizadas palestras e aulas dialogadas e interativas sobre a temática, abordando a chegada dos povos africanos no Novo Mundo, o campo religioso afro-brasileiro, etc. Além das regências e palestras, o projeto foi composto por filmes, rodas de conversa e se desdobrou em oficinas de capoeira, onde foram ministradas aulas práticas pelo residente. Nelas ocorriam as explicações e discussões sobre o contexto histórico da capoeira e as 
ladainhas que são entoadas para o jogo. Em apoio à formação continuada, o residente participou na aplicação de atividades interativas na sala de multimídia (jogo interativo caminhos da África), alcançando professores de diferentes áreas. Estudantes de diversas turmas participaram das atividades e palestras e cerca de 30 frequentaram as oficinasem horários alternados. A culminância deste projeto foi no dia da mostra cultural da escola contando com a presença de um mestre e seu grupo em uma grande roda com a participação de diversos estudantes, mesmo os que não estavam acompanhando as oficinas.

\section{Literatura afro-brasileira com foco nas escritoras negras}

As atividades desta residente foram desenvolvidas de forma interdisciplinarcom a Sociologia e a Literatura, tratando da temática étnico-racial por meio da produção literária. As ações didático-pedagógicas se iniciaram pela discussão de percursos escolares envolvendo as possibilidades da escrita para, em seguida, apresentar expoentes da literatura e intelectuais negras desconhecidas do grande público e cujas obras, em geral, não são adotadas como referências nas escolas. Dentre as ações, os estudantes foram indagados sobre a representatividade negra nos meios de comunicação, ao que se seguiu a discussão acerca da invisibilidade desses intelectuais e de escritoras negras, como Conceição Evaristo e Carolina Maria de Jesus. Todas estas ações foram trabalhadas por meio da apresentação, interpretação e discussão dos textos em saraus, garantindo espaço para a produção textual dos estudantes, realizada durante o processo. Ao final do ciclo foram produzidos fanzines com os textos e ilustrações dos estudantes, os quais foram expostos na mostra cultural da escola, em um varal literário.

\section{Um caminho de possibilidades: formação de professores, perspectiva sociológica e antirracista}

Para os residentes, a formação docente apresenta muitos desafios. Quando instados a enfrentá-los no cotidiano da prática docente, percebemos a dimensão cognitiva desse desafio de ministrar os conteúdos alusivos à educação das relações étnico-raciais. Os caminhos para esse enfrentamento são apontados por Oliveira (2014), quando pondera que

\footnotetext{
O aspecto cognitivo refere-se à necessidade que esses professores têm de desconstruir saberes científicos e históricos, construir novas leituras e interpretações no campo do conhecimento histórico e superar as lacunas da formação inicial docente e incorporá-las como uma nova identidade profissional. Porém essa tarefa não é isolada; insere-se também no campo pedagógico. Nesse sentido, são tencionados a reorientarem seus saberes da experiência nas relações raciais diante das posturas preconceituosas dos alunos e colegas de profissão, na medida em que devem encontrar mecanismos inovadores e inventarem situações didáticas para a desconstrução do senso comum e dos preconceitos. Essa é uma tensão formativa que se apresenta permanentemente e que se encontra no âmbito epistemológico e identitário (Oliveira, 2014, p. 85).
}

A desconstrução dos saberes consolidados no senso comum é um recurso metodológico bastante utilizado nas Ciências Sociais, mas como mencionou o autor, nem sempre fácil aos novos professores. E quando lidam com a questão racial no cotidiano da sala de aula, eles encontram outras ainda barreiras, o que requer uma formação específica, pois em geral os cursos de graduação, e de licenciatura, não tem discutido a questão satisfatoriamente, quando o fazem. Cientes dessas dificuldades e informadas sobre demandas de outros segmentos, compusemos um grupo que elaborou e implementou um curso de formação para a temática étnico-racial em 2019, para o qual os residentes foram convidados a participar. Dos onze residentes, quatro 
se candidataram e foram selecionados para o curso e puderam desenvolver simultaneamente projetos de pesquisa, ensino e extensão na escola campo, dentro da temática étnico-racial.

O "Curso de Formação e Pesquisa em Educação das Relações Étnico-Raciais" foi uma proposta de formação firmada para atender à demanda do Núcleo de Estudos Afro-Brasileiros da UFES em parceria com o Ministério Público Estadual - MPES. A formação foi pensada e estruturada para o público formado por professores, gestores de escolas e técnicos que atuam diretamente na educação básica, além de funcionários do MP/ ES, ativistas, militantes universitários voltados ao diálogo e ao enfrentamento ao racismo na sociedade, bem como aos estudantes finalistas de licenciatura em Ciências Sociais da UFES, vinculados ao Programa Residência Pedagógica.

A formação teve $120 \mathrm{~h}$ de carga horária, distribuídas em encontros presenciais na universidade, na sede no MPES, em Vitória/ES e aulas de campo na região metropolitana. Contamos ainda com atividades não presenciais por meio do aplicativo Google Sala de Aula, onde postamos artigos, atividades, indicações de leituras, dentre outros.

O curso se estruturou a partir de encontros quinzenais, no período noturno, com duração de 4 h e oficinas e aulas de campo aos sábados pela manhã, além de dois encontros destinados aos seminários de abertura e de encerramento no período vespertino. Nos encontros foram abordados temas específicos sobre a ERER, e o último encontro da formação foi dedicado à apresentação de projetos de intervenção dos cursistas. Os residentes prepararam as suas propostas de intervenção, que foram desenvolvidas na escola campo, onde já estavam atuando no PRP.

Durante a participação dos residentes na formação, coletamos alguns relatos sobre a temática da Educação das Relações Étnico-Raciais - ERER na escola de atuação e no curso de Ciências Sociais. Os relatos apresentados pelos quatro residentes nos fizeram refletir sobre a ausência de discussão teórica e prática e a necessidade da inserção de disciplinas obrigatórias não somente no curso de licenciatura de Ciências Sociais, mas em todas as licenciaturas de instituições públicas ou privadas. Destacamos a importância do cumprimento da Lei $n^{\circ} 10.639 / 2003$ com a proposta de ensinar a todas/os a História e Cultura Afro-Brasileira e Africana, de acordo com o Art. $1^{\circ}$ da Resolução $n^{\circ} 1$, de 17 de junho de 2004:

A presente resolução institui diretrizes Curriculares Nacionais para a Educação das Relações ÉtnicoRaciais e para o Ensino de História e Cultura Afro-Brasileira e Africana, a serem observadas pelas Instituições de ensino, que atuam nos níveis e modalidades da Educação Brasileira e, em especial, por Instituições que desenvolvem programas de formação inicial e continuada de professores.

$\S 1^{\circ}$ As Instituições de Ensino Superior incluirão nos conteúdos de disciplinas e atividades curriculares dos cursos que ministram, a Educação das Relações Étnico-Raciais, bem como o tratamento de questões e temáticas que dizem respeito aos afrodescendentes, nos termos explicitados no Parecer CNE/CP 3/2004.

$\S 2^{\circ} \mathrm{O}$ cumprimento das referidas Diretrizes Curriculares, por parte das instituições de ensino, será considerado na avaliação das condições de funcionamento do estabelecimento (BRASIL, 2004, p. 31).

Há a necessidade e urgência da oferta de conteúdos e disciplinas voltadas para a ERER na formação inicial, ou seja, a formação é importante para conscientizar e apontar possibilidades de conhecimento teórico e prático para as/os futuras/os professoras/es. Inspirando-nos em Freire (1996), intentamos atuar de maneira proativa para promover transformações na história e na sociedade em que vivemos, pois 
O fato de me perceber no mundo, com o mundo e com os outros me põe numa posição em face do mundo que não é de quem nada tem a ver com ele. Afinal, minha presença no mundo não é a de quem a ele se adapta mas a de quem nele se insere. É a posição de quem luta para não ser apenas objeto, mas sujeito também na história (FREIRE, 1996, p. 31).

Ao acompanharmos os residentes, percebemos que a tomada de consciência foi adquirida paulatinamente, a partir dos desafios da atuação prática. Alguns residentes mesmo sem ter base teórica já buscavam nas aulas de Sociologia enfrentar o racismo com propostas de intervenção que dialogassem com a realidade dos alunos da escola-campo. Essa tomada de consciência nos remete à reflexão de Freire (1996), quando nos diz que

A consciência do mundo e a consciência de si inacabado necessariamente inscrevem o ser consciente de sua inconclusão num permanente movimento de busca. Na verdade, seria uma contradição se, inacabado e consciente do inacabamento, o ser humano não se inserisse em tal movimento (FREIRE, 1996, p. 33-34).

A partir da percepção dessa tomada de consciência nos projetos desenvolvidos pelos residentes, em determinado momento, os indagamos para saber em que aspectos o curso de formação influenciou suas percepções sobre a ERER, e obtivemos como respostas:

O curso me despertou uma necessidade imensa de estudo e do diálogo do tema ERER. Percebi a necessidade dessa discussão na escola, na família, com amigos e em todos os espaços sociais dos quais faço parte. Juntamente com o curso de ERER na UFES eu fazia um curso de Formação Política no IFES e passei a levantar a bandeira em todos os temas discutidos, lembro-me de dizer diversas vezes para os colegas do curso que era impossível discutir qualquer assunto político e social no Brasil se não levarmos em consideração as desigualdades raciais (Residente A, 2019) ${ }^{6}$.

A constatação da necessidade desse aporte teórico-metodológico para as discussões cotidianas, ainda foi mencionada nas falas de outros residentes, como vemos abaixo:

Só aumentou a minha convicção de que as formações em ERER devem ser requisitos obrigatórios para qualquer profissional da educação e também da área da saúde (Residente C, 2019).

A nossa presença na escola era para aprender na prática como funciona o ambiente escolar e também contribuir e participar ativamente da rotina da escola. A formação ERER me deu base para a Residência Pedagógica, no sentido de conseguir colocar em prática algo que em mim estava vago. Nesse sentido, a formação me deu mais conteúdo para aplicar pesquisas e lecionar em sala de aula (Residente D, 2019).

Diante dos argumentos apresentados, enfatizamos a importância das ações afirmativas e de cobrarmos coletivamente pela implementação das leis já aprovadas, como a Lei nº 10.639/2003, voltada para a educação, tanto o ciclo básico como o ensino superior. Destacamos ainda a importância da inclusão do entendimento teórico sobre o que é o racismo, a discriminação racial e o preconceito, pois segundo Gomes (2005) esse aporte conceitual

[...] poderia ajudar os(as) educadores(as) a compreenderem a especificidade do racismo brasileiro e auxiliá-los a identificar o que é uma prática racista e quando esta acontece no interior da escola. Essa é uma discussão que deveria fazer parte do processo de formação dos professores (GOMES, 2005, p. 148).

6 Ocultamos os nomes para proteger a identidade dos envolvidos. 
Observamos que a discussão conceitual é necessária para a adoção de práticas concretas e complementa a formação da licenciatura, conforme observam os residentes quando indagados sobre a relevância do curso de formação em ERER e a relação com a licenciatura:

Devido à formação eurocêntrica que recebemos na academia, eu venho estudando as relações raciais a algum tempo, antes mesmo da formação em ERER pelo NEAB, e a formação em ERER possibilitou ouvir as experiências de educadores em seu ambiente de trabalho (Residente C, 2019).

A formação me possibilitou aprofundamento a um tema pouco discutido na formação da licenciatura na universidade. Eu já havia tido contato com uma disciplina optativa com a mesma temática na universidade, apesar do pouco tempo da disciplina ela me gerou uma necessidade de aprofundar a discussão, já que serei professor e o tema é discutido de forma muito precário nas escolas públicas. O curso me empoderou e despertou em mim uma afinidade muito grande com o tema das relações étnico-raciais e a necessidade de constante aprofundamento. Como resultado, aumentei minha leitura de artigos e livros com a temática. O tema passou a fazer parte do meu diálogo com a família, amigos, colegas, alunos, em todos os espaços sociais aos quais faço parte (Residente A, 2019).

Ainda sobre a importância da formação em ERER, concordamos com Gomes (2005) quando nos propõe a pensar na possibilidade de construir experiências de formação para que professores vivenciem, analisem e proponham estratégias de intervenção que valorizem a cultura negra, eliminando as práticas racistas em nossas instituições de ensino.

Para o ensino de Sociologia na educação básica, as Orientações Curriculares para o Ensino MédioSociologiasaventam diversas possibilidades para além das aulas expositivas. A Sociologia no ensino médio pode ser desenvolvida de diferentes formas e com múltiplosrecursos didáticos, como seminários, excursões, visitas a museus, parques ecológicos, leitura e análise de textos, cinema, fotografia, charges, cartuns, tiras, músicas, dentre outros (BRASIL, 2006). Estas abordagens metodológicas desempenham uma importante função "[...] para tornar o conhecimento sociológico acessível aos/às estudantes do Ensino Médio" (SOUZA, 2017, p. 73).

E acrescentamos ainda que, segundo as Diretrizes Curriculares Nacionais para a Educação das Relações Étnico-Raciais, o ensino de História e Cultura Afro-Brasileira e Africana deve ser promovido pelas diferentes disciplinas que compõem o currículo da educação básica (BRASIL, 2004). A Sociologia, portanto, também deve promover a inclusão do conteúdo prescrito na Lei n 10.639/2003, e acreditamos que os residentes pedagógicos desempenharam essa função nas aulas de Sociologia, para a qual contaram com o suporte da formação em ERER.

Uma ação que consideramos essencial para possibilitar maior aproximação entre teoria e prática às/aos professoras/es é refletir sobre o processo formativo. Referimo-nos à formação inicial, pois é o momento de aprendizado teórico e prático do futuro professor de Sociologia.

Muitas dificuldades foram encontradas pelos residentes ao se deparar com a realidade prática da sala de aula e com o racismo perverso presente no cotidiano de nossos estudantes. E muitas dificuldades foram refletidas a partir das falhas na formação inicial, pois não nos foi "ensinado" como lidar com essas questões, com o racismo e com um sistema racista. Com isso, concordamos com Cruz, Oliveira e Lins (2016), ao nos apresentarem a seguinte proposição: 
Não existe uma receita pedagógica para orientar e propor ações didáticas para o fazer antirracista no ensino de Sociologia. Essa proposta seria uma pretensão que não levaria em conta os diversos contextos sociais e pedagógicos escolares e universitários, como também não consideraria o fato de que são os docentes, mergulhados nos processos de ensino-aprendizagem, que devem, sabem e podem construir um conhecimento escolar em sociologia antirracista (CRUZ; OLIVEIRA; LINS, 2016, p. 52).

Dessa forma, compreendemos a importância da formação prática e teórica que constantemente foi relatada pelos residentes, bem como a importância da Sociologia na educação básica, possibilitando aos futuros profissionais da educação a consciencialização para a o enfrentamento do racismo. 


\section{Considerações Finais}

Observamos que a participação dos residentes pedagógicos e do professor preceptor no Programa Residência Pedagógica foi uma experiência inovadora e exitosa no que se propôs a fazer. Ou seja, o PRP conseguiu realizar a discussão de conteúdos, estratégias, novos formatos e uso de recursos e novas tecnologias que foram experimentadas na prática, no cotidiano escolar. Possibilitou ainda a aplicação dos planos de ação traçados individualmente pelos residentes, com criatividade einventividade em torno dos desafios colocados, possibilitando planejamento e a execução por vezes coletivas. O prazo de execução do projeto, dezoito meses, propiciouque as ações didático-pedagógicas envolvendo ensino, pesquisa e extensãofossem replicadas em diferentes turmas e nos dois turnos, possibilitandoavivência mais intensa dos residentesna escolae também que eles pudessem fazer adaptações necessárias aos diferentes perfis de estudantes e turmas.Nesse tempo pudemos planejar e executar a formação para a ERER, que se mostrou necessária. As ações desenvolvidas, não só elevaram a qualidade da formação inicial de professores no curso de licenciatura, fato que eles unanimemente reconheceram nos relatórios e depoimentos, mas também promoveram a formação continuada do professor preceptor e dos demais que participaram no processo, o que inclui as coordenadoras pedagógicas. A esse saldo positivo se soma o aumento de interesse dos estudantes pela abordagem sociológica da realidade e a busca aos residentes para dialogar sobre temas poucodebatidos ou considerados tabus na educação básica, como religiosidade, sexualidade e questões de gênero, estigmas, preconceitos e racismo. No que tange à formação para trabalhar com a temática étnico-racial na disciplina Sociologia, observamos que ela desempenhou papel fundamental para instrumentalizar os novos professores a enfrentarem os desafios epistemológicos e práticos neste campo profissional. A formação, além de contribuir com os conteúdos e a possibilidade de uma didática antirracista, possibilita a reflexão sobre a importância da discussão racial ou da falta dela no cotidiano escolar, e do quanto podemos contribuir para o avanço das relações raciais nesse lugar e fora dele. Por fim, não podemos deixar de reconhecer as limitações para o desenvolvimento das atividades, tendo em vista que a disciplina conta somente com uma aula semanal por turma, o que dificulta a continuidade dentro de uma proposta dialógica. Outras dificuldades mostram-se notórias no atual contexto de recrudescimento do pensamento conservador em nosso país, fazendo com que algumas barreiras se tornem mais rígidas, especialmente as que são influenciadas por preconceitos e estereótipos alçados a verdades nas mídias sociais. A vigilância que tem sido imposta à atividade docente faz com que muitas vezes tenhamos a nítida impressão de que o/a professor/a de sociologia é cada vez mais uma voz solitária na escola. 


\section{REFERÊNCIAS}

BARREIRO, Iraíde Marques de Freitas; GEBRAN, Raimunda Abou. Prática de ensino: elemento articulador da formação do professor. IN: BARREIRO, Iraíde Marques de Freitas; GEBRAN, Raimunda Abou. Prática de ensino e estágio supervisionado na formação de professores. São Paulo: Avercamp, 2006.

BRASIL. Diretrizes Curriculares Nacionais para a Educação das Relações Étnico- Raciais e para o Ensino de História e Cultura Afro-Brasileira e Africana. Brasília, 2004.

BRASIL. Presidência da República. Lei 10.639 de 9 de janeiro de 2003(b). Altera a Lei n 9.394, de 20 de dezembro de 1996, que estabelece as diretrizes e bases da educação nacional, para incluir no currículo oficial da Rede de Ensino a obrigatoriedade da temática "História e Cultura Afro-Brasileira", e dá outras providências. Diário Oficial da União. Brasília, DF, 10 jan. 2003, p. 1. Disponível em:http://www.planalto.gov.br/ccivil_03/ leis/2003/l10.639.htm. Acesso em: 15 ago. 2020.

BRASIL. Resolução CNE/CP n ${ }^{\circ}{ }^{\circ}$, de 17 de junho de 2004(b). Institui Diretrizes Curriculares Nacionais para a Educação das Relações Étnico-Raciais e para o Ensino de História e Cultura Afro-Brasileira e Africana. Diário Oficial da União, Brasília, DF, 22 jun. de 2004, Seção 1, p. 11. Disponível em:http://portal.mec.gov.br/cne/ arquivos/pdf/res012004.pdf. Acesso em: 10 ago. 2020.

BRASIL. Orientações Curriculares para o Ensino Médio. OCN-EM. Ciências Humanas e suas Tecnologias/ Secretaria de Educação Básica. Brasília: Ministério da Educação, Secretaria de Educação Básica, 2006.

CLIFFORD, James. A experiência etnográfica: antropologia e literatura no século XX. Org. José Reginaldo Santos Gonçalves. Editora: UFRJ, 2008. Cap. 1 [p.17-58].

CRUZ, Eliane A. de S. ; OLIVEIRA, Luiz Fernandes; LINS, Mônica Regina F. Ensino de Sociologia Antirracista: reflexões sobre formação docente. Inter-Legere, Natal, n 18, 2016.

FREIRE, Paulo. Pedagogia da Autonomia: saberes necessários à prática educativa. 30a ed. Rio de Janeiro: Editora Paz e Terra, 1996.

GEERTZ, Clifford. A interpretação das Culturas. Rio de Janeiro: Editora SA, 2008.

GOMES, Nilma Lino. Educação e Relações Raciais: refletindo sobre algumas estratégias de atuação. In: MUNANGA, Kabengele (Org.). Superando o racismo na escola.2a.ed. rev. Brasília: Ministério da Educação, Secretaria de Educação Continuada, Alfabetização e Diversidade, 2005, p. 143-154.

MALINOWSKI, Bronilaw. Os argonautas do pacífico Ocidental. Abril: São Paulo, 1973.

MEUCCI, Simone. (2000), Institucionalização da sociologia no Brasil: os primeiros manuais e cursos. Dissertação de mestrado, Campinas, Unicamp, mimeo. Disponível em: http://repositorio.unicamp.br/jspui/ handle/REPOSIP/279132? mode=full

MORAES, Amaury Cesar. Licenciatura em ciências sociais e ensino de sociologia:entre o balanço e o relato. Tempo soc. vol.15 no.1 São Paulo Apr. 2003. 
OLIVEIRA, Luiz Fernandes de. Educação Antirracista: tensões e desafios para o ensino de sociologia.in: Educação \& Realidade, Porto Alegre, v. 39, n. 1, p. 81-98, jan./mar. 2014. Disponível em: http://www.ufrgs. br/edu_realidade.

PIMENTA, Selma G., LIMA, Maria S. L.. Estágio e docência: diferentes concepções. inRevista Poíesis - Volume 3, Números 3 e 4, pp.5-24, 2006

SILVA, Ileisi F. A sociologia no ensino médio: os desafios institucionais e epistemológicos para a consolidação da disciplina. Cronos, Natal-RN, v. 8, n. 2, p. 403-427, jul./dez. 2007.

SOUZA, Erivelto Santiago. Processos educativos em práticas docentes de sociologia: perspectivas para a educação das relações étnico-raciais no ensino médio. 2017. 254 f. Tese. São Carlos: Programa de PósGraduação em Educação da Universidade Federal de São Carlos, 2017. 